$1-2018$

\title{
The Treatment Planning of Experienced Counselors: A Qualitative Examination
}

Daniel Gutierrez

William \& Mary, dgutierrez@wm.edu

Jesse Fox

Kendra Jones

Elizabeth Fallon

Follow this and additional works at: https://scholarworks.wm.edu/aspubs

Part of the Clinical Psychology Commons, and the Counseling Commons

\section{Recommended Citation}

Gutierrez, Daniel; Fox, Jesse; Jones, Kendra; and Fallon, Elizabeth, The Treatment Planning of Experienced Counselors: A Qualitative Examination (2018). Journal of Counseling \& Development, 96(1), 86-96.

https://doi.org/10.1002/jcad.12180

This Article is brought to you for free and open access by the Arts and Sciences at W\&M ScholarWorks. It has been accepted for inclusion in Arts \& Sciences Articles by an authorized administrator of W\&M ScholarWorks. For more information, please contact scholarworks@wm.edu. 


\title{
The Treatment Planning of Experienced Counselors: A Qualitative Examination
}

\author{
Daniel Gutierrez, Jesse Fox, Kendra Jones, and Elizabeth Fallon
}

Using consensual qualitative research, the authors examined the treatment planning process of experienced counselors $(N=9)$. The data analysis resulted in 4 domains: assessment steps, clinical impressions, treatment factors, and treatment strategies. These domains describe the process used by experienced counselors in making clinical decisions and offer insight into the nature of clinical expertise and the need for further research on treatment planning.

Keywords: clinical mental health counseling, treatment planning, common factors, REPLAN model, contextual approach

The need for an effective treatment planning approach is illustrated in the standards for the accreditation of counseling programs (Council for the Accreditation of Counseling and Related Educational Programs, 2015) and the ACA Code of Ethics (American Counseling Association [ACA], 2014). Treatment planning is an essential task that every practicing counselor must carry out. However, research on treatment planning is scarce. Falvey, Bray, and Hebert (2005) reported that despite extensive empirical literature in cognitive psychology, researchers have failed to "lessen the considerable variability that exists between what is known about clinical decision-making and what is practiced" (p. 349). Although research has consistently confirmed that counseling is more effective than no treatment (Lambert, 2007, 2013a, 2013b; Norcross \& Wampold, 2011), what is being done in counseling sessions may significantly vary from counselor to counselor (Witteman \& Koele, 1999; Witteman \& Kunst, 1997). In addition, because much of psychotherapy and counseling is determined by clinical judgment, little is known about what influences treatment planning.

Counselors have recommended various treatment planning models as frameworks for making clinical decisions. The oldest and most recognizable framework is the diagnostic approach based on the medical model (Wampold, Ahn, \& Coleman, 2001). This approach likens counseling to medicine and is based on the premise that a diagnosis should dictate treatment (Wampold et al., 2001; Wampold \& Imel, 2015). For example, if a client is experiencing depression, the diagnostic approach suggests that the client should be treated with cognitive behavior therapy or another similar empirically supported treatment, regardless of the client's clinical context. This premise is difficult to maintain when one considers that research supports the use of different approaches for the same diagnosis. For example, both cognitive therapy and interpersonal therapy have been identified as effective treatments for depression (Lambert, 2013a; Seligman \& Reichenberg, 2014; Wampold \& Imel, 2015).

Alternatively, counselors could base their treatment decisions on counseling theory. For example, a counselor working from a specific theoretical perspective (e.g., cognitive therapy) may develop treatment plans consistent with an emphasis on that approach (e.g., focus on challenging cognition). In a comparative study of psychotherapy approaches, Frank and Frank (1991) noted that theory and clinical philosophy provide a unique set of therapeutic activities with their own relative emphasis. However, most counselors find that clients benefit from the integration of various approaches (Frank \& Frank, 1991). In addition, research has shown that the effectiveness of counseling is chiefly attributed to the factors that these approaches have in common as opposed to how they differ (Frank \& Frank, 1991; Lambert, 2007, 2013a, 2013b; Lambert \& Ogles, 2014; Laska \& Wampold, 2014; Wampold \& Imel, 2015). This supposition — that the majority of what is effective about counseling approaches is attributable to factors common to all of the approaches - is known as common factors theory and is the subject of a considerable amount of research (Lambert \& Ogles, 2014; Laska, Gurman, \& Wampold, 2014; Laska \& Wampold, 2014; Norcross \& Wampold, 2011; Wampold, 2013, 2015).

\footnotetext{
Daniel Gutierrez, Kendra Jones, and Elizabeth Fallon, Department of Counseling, University of North Carolina at Charlotte; Jesse Fox, Pastoral Counseling Department, Loyola University Maryland. Daniel Gutierrez is now at Department of School Psychology and Counselor Education, College of William and Mary. Jesse Fox is now at Department of Counselor Education, Stetson University. Correspondence concerning this article should be addressed to Daniel Gutierrez, School of Education, College of William and Mary, PO Box 8795, Williamsburg, VA 23187 (e-mail: dgutierrez@ wm.edu).
}

(C) 2018 by the American Counseling Association. All rights reserved. 
Moreover, when counseling approaches are directly compared on their effectiveness, no approach has emerged as being more efficacious than any other (Lambert, 2013a; Wampold \& Imel, 2015). The lack of evidence supporting a single superior treatment is known as the dodo bird hypothesis (Frank \& Frank, 1991; Marcus, O’Connell, Norris, \& Sawaqdeh, 2014). The dodo bird hypothesis (also known as the dodo bird verdict) is a reference to the children's story Alice's Adventures in Wonderland, in which several characters who have gotten wet are told by the Dodo bird to run in a race in order to get dry. When they ask the Dodo bird for his verdict on the winner, he declares, "Everybody has won so all shall have prizes" (Luborsky et al., 2002). Rosenzweig (1936) used this story to describe how, when varying counseling theories are compared on their effectiveness, they all demonstrate efficacy and all have merit (i.e., they all win and all get prizes). The term dodo bird hypothesis is used to describe the lack of statistically significant differences between therapeutic approaches (Luborsky et al., 2002; Rosenzweig, 1936; Wampold \& Imel, 2015), which suggests that basing treatment planning decisions solely on theoretical grounds may not be as advantageous as is often hypothesized.

Citing the dodo bird hypothesis, Wampold (2015) suggested that counseling treatment should take into account contextual factors, such as client expectation, therapist and client attributes, and cultural factors. He indicated that effective treatment planning must look beyond theory and diagnosis and match a client to the most appropriate treatment (Wampold, 2015). Emerging research has confirmed this assertion and shown that treatment matching leads to greater outcomes and a strengthened therapeutic alliance (Beutler, Forrester, Gallagher-Thompson, Thompson, \& Tomlins, 2012; Swift, Callahan, Ivanovic, \& Kominiak, 2013; Wampold \& Imel, 2015). Unfortunately, these contextual factors are often missing from traditional treatment planning models, thus making treatment matching difficult.

The Contextual Model (Wampold \& Imel, 2015) and the REPLAN model (Young, 2012) are treatment planning models developed to provide a framework for counselors to match clients to effective treatments based on contextual factors. The Contextual Model is based on the premise that the benefits of counseling are produced through three common pathways: (a) the real relationship, (b) expectations, and (c) specific ingredients (Wampold, 2015). The real relationship refers to the therapeutic alliance established between the client and the counselor, expectations are the client's belief that the treatment will help him or her and that the client can do what is necessary to get better, and specific ingredients are the techniques and interventions used by the counselor to address the presenting concern. From this perspective, treatment planning would consist of matching clients to a theoretical rationale that both the counselor and client agree upon, focusing on building a relationship, developing client expectations, and applying interventions that are consistent with the agreed-upon rationale (Wampold, 2015; Wampold \& Imel, 2015). The REPLAN model uses the same underlying premise of matching clients to the most appropriate treatment but bases the process on common factors theory and current research (Young, 2012). REPLAN stands for establishing and maintaining a strong helper-client relationship; enhancing efficacy and self-esteem; practicing new behaviors; lowering and raising emotional arousal; activating client expectations, hope, and motivation; and providing new learning experiences. Treatment planning using the REPLAN model involves building a strong therapeutic relationship, formulating the goals of treatment, and then matching the client's goals and presenting concerns with one of the common factors (e.g., enhancing efficacy and self-esteem). These two approaches are unique because rather than using diagnosis or theory to direct their treatment planning process, they consider the client characteristics and context.

Another consideration in treatment planning is the role of clinical judgment and intuition. Counselors traditionally recognize clinical judgment and intuition as being just as influential in their work as clinical research (Baker, McFall, \& Shoham, 2008; Gaudiano, Brown, \& Miller, 2011; Lucock, Hall, \& Noble, 2006). Studies comparing theoretical orientation and clinical judgment have found that when therapists have comparable levels of clinical experience, they tend to focus on the same or noticeably similar clinical material in their clinical decision making (Eells, 1999; Kealy, Goodman, Rasmussen, Weideman, \& Ogrodniczuk, 2015). Just as there appear to be common factors between effective theoretical orientations, research suggests that there are common cognitive patterns that clinicians use to decide what therapeutic directions are important to explore with clients (Fox, Hagedorn, \& Sivo, 2016).

These studies are important contributions to understanding how counselors make clinical decisions, yet important questions about how such judgments form a treatment plan are unexplored. The purpose of this study was to develop a clearer understanding of how experienced counselors practice treatment planning. Specifically, we explored how experienced counselors arrive at treatment planning decisions and what factors they consider in their treatment planning process. Whereas previous research has emphasized cognition and judgment patterns in treatment planning, this study proposed to remain exploratory and focused on the counselors' experience. The following research question guided our investigation: "How do experienced counselors describe their treatment planning process?"

\section{Method}

Given the exploratory nature of this investigation and the complexity of the topic, we determined that a qualitative 
approach would provide us with the most effective way of answering our research question. Qualitative inquiry allows for researchers to explore complex questions using a holistic approach that values subjective meaning, takes context into consideration, and amplifies the phenomenological experience of the participant (Hays \& Singh, 2012). We selected a qualitative approach because it allowed us the greatest opportunity of exploring the counselors' treatment planning experience without having to reduce their process to predetermined constructs. Specifically, this study used consensual qualitative research (CQR; Hill, 2012; Hill et al., 2005; Hill, Thompson, \& Williams, 1997). CQR is a qualitative approach to research designed to integrate the methods of other qualitative approaches with an emphasis on rigor (Hill et al., 2005). $\mathrm{CQR}$ uses open-ended questions, semistructured interview protocols, a research team to evaluate the data until consensus is reached, and an auditor to further validate the data analysis (Hill et al., 1997, 2005). These distinctive features of CQR allowed us to immerse ourselves in the data analysis and ensure that there was depth in our findings.

\section{Participants}

Hill et al. (2005) described a strong sample size for CQR to be between eight and 15 participants. This study consisted of a purposive sample of nine professional counselors. The inclusion criteria were as follows: (a) have a minimum of 10 years of professional counseling experience, (b) be a licensed professional counselor or have held a professional license, (c) still see clients in some capacity (either as an active clinician or as a counselor educator conducting supervision or clinical research), and (d) have experience teaching or supervising counseling interns. The inclusion criteria were gathered from a review of the literature on clinical expertise. Of those who agreed to participate in the study, two identified as female and seven identified as male. In terms of race, eight participants identified as White and one identified as other. In terms of ethnicity, four participants identified as Caucasian, one as Latino, one as East European, and one as German/Norwegian descent; two participants did not provide a response. The age of the participants ranged from 36 to 68 years, with a mean age of 50 years $(S D=12.04)$. As previously mentioned, all participants had practiced for a minimum of 10 years; however, participant experience ranged from 10 to 35 years. In addition, eight of the nine participants held a $\mathrm{PhD}$ in counseling or a counseling-related subject (e.g., counselor education). In terms of theoretical orientation(s), participants described themselves as using Jungian theory $(n=1)$, psychodynamic therapy $(n=1)$, object relations theory $(n=1)$, existential therapy ( $n=1)$, motivational interviewing $(n=2)$, cognitive behavior therapy $(n=2)$, client-centered therapy $(n=3)$, and experiential therapy $(n=1)$; one participant described himor herself as using a "problem-focused" and family systems approach. Four participants described themselves as using an integrated combination of several of the approaches listed.

\section{Research Team}

One of the premises of CQR is that multiple viewpoints ensure more trustworthy results (Hill, 2012). Therefore, a chief component of CQR is the use of a research team during the coding and data analysis process. Our research team consisted of two male faculty members and two female graduate students in the counseling program. To manage the power differential throughout the research process, we alternated leading the group meetings and each research team member took turns presenting his or her perceptions on the topic. In addition, prior to beginning any data collection, we took part in two bracketing exercises. First, each of us wrote brief reflexivity statements describing our thoughts, perceptions, and personal beliefs about counseling and treatment planning. Second, we openly discussed our experiences on the research team prior to each meeting. Research team members were encouraged to express if they felt uncomfortable or pressured on the project.

\section{Procedure}

After receiving approval from the institutional review board, the research team began recruiting participants using chainreferral sampling (i.e., snowball technique). Initial participants were identified from the ACA directory of fellows and through their national reputation as counseling professionals. Each potential participant was invited for the interview via e-mail and was given the opportunity to review the informed consent and study procedures before the interview. Research team members contacted participants to schedule an interview time and date. Because participants were spread throughout the country, face-to-face interviews were not possible. Thus, all participants were interviewed and digitally recorded over the phone. Participants received a $\$ 40$ Amazon gift card for completing the interview.

During the interview, research team members provided participants with a secure link to an electronic-based survey (Qualtrics). Using the link, participants completed a list of demographic questions and then watched a 10-minute video vignette of a client presenting a clinical concern. The video vignette used in this study depicted a brief interaction between a counselor and a client. The video is of one static shot of the client sitting in a chair (the client's whole body is seen in the video) facing the camera. A counselor is in the room with the client, but the counselor sits off camera and is only there for the purposes of encouraging the client to explore her story further. The research team instructed the client, a volunteer from the university, to describe a presenting concern that was important and troubling to her. The client discussed conflict within her family due to a recent divorce between her parents. The client also discussed feelings of stress related to work and school 
obligations, as well as conflicting roles as a daughter, student, employee, and sister. The client was lucid, attentive, and engaged throughout the interview. At several points throughout the interaction, the client became tearful and expressed sadness and elements of grief.

As participants watched the video, researchers asked them to think aloud and reflect on their initial impressions of the client and treatment strategy. Subsequently, the interviewer conducted a semistructured interview to explore the counselor's treatment planning process. Questions used in the interview included (a) "Describe your initial impressions of the client," (b) "Describe your next steps in working with this client," and (c) "What features do you think are most important for your treatment strategy?" Prior to conducting the first interview, we pilot tested the interview protocol, video, and complete procedures on two professional counselors. The research team met after the pilot test to modify and strengthen the final procedures by clarifying confusing questions and improving the interview process. We then began contacting and interviewing participants. The research team transcribed each interview.

\section{Trustworthiness}

In qualitative research, establishing trustworthiness is critical to the validity of the findings (Hays \& Singh, 2012). According to Hill et al. (1997), three criteria are required to establish the trustworthiness of a CQR study. The first is trustworthiness of the method, which pertains to the measures used to establish the quality of the analysis. To establish the trustworthiness of the method, we pilot tested our interview questions and protocol, independently coded each transcript and then worked as a group to reach consensus, used an independent external auditor, and conducted bracketing exercises to monitor bias and the power dynamics of the group. The second criterion is coherence of results and consists of the methods taken to ensure that the inferences made with the data make logical sense to the outside reader. In CQR, the use of a research team and the requirement of reaching consensus help to establish the coherence of the results. However, the external auditor was also useful in ensuring that our inferences were logical and linear. The third required criterion for trustworthiness is the representativeness of the results. To demonstrate the representativeness of our results, we documented the frequency and consistency of each theme using the recommended categories of general, typical, and variant. Other steps taken to establish trustworthiness included (a) using direct quotes from participants and verbatim transcription, (b) establishing the applicability of our findings by comparing them to existing research, (c) using separate journal notes to document our individual experiences before meeting as a group, and (d) using a research team to evaluate codes.

\section{Data Analysis}

In CQR, the data analysis process consists of three steps: (a) developing domains, (b) constructing core ideas from the content of each domain, and (c) cross analyzing the data to ensure the validity of categories across cases (Hill et al., 1997). The analysis process began with each member of the research team independently reading the first two transcripts and developing a list of domains. The research team members then met and presented their lists of domains and reached consensus on a single agreed-upon list. Then, each member of the research team independently coded each transcript using the final list of domains as a guide. Subsequently, the team met and discussed each transcript until consensus was reached on the specific codes. The team then cross analyzed the final codes to ensure that the same ideas were represented throughout all of the transcripts, reducing and collapsing codes as needed. Finally, to demonstrate the representativeness of the codes across the cases, we categorized each code in terms of frequency. Hill et al. (2005) suggested the categories general if a theme is found in all cases, typical if the theme is found in at least half the cases, and variant if the theme is in less than half but at least two cases. Accordingly, we categorized codes as being general if it was found in all nine interviews, typical if it was in at least five interviews, and variant if it was in at least two interviews. Throughout the process of coding the transcripts, we submitted the transcripts, codes, and the list of domains to an external auditor who reviewed our themes and conducted an independent cross analysis to ensure accuracy and clarity of the themes.

\section{Results}

Our analysis resulted in four domains: (a) assessment steps, (b) clinical impressions, (c) treatment factors, and (d) treatment strategies. The first domain, assessment steps, consisted of areas the counselors explored to get further information about what treatment approach would work best. The second domain, clinical impressions, consisted of the reactions the counselor had to the client that informed their treatment planning process. The third domain, treatment factors, referred to factors that influenced treatment decisions, such as client level of readiness or personality factors. Finally, the fourth domain, treatment strategies, referred to the techniques that the counselors thought were appropriate to use with the client in session.

\section{Assessment Steps}

The domain labeled assessment steps was made up of five themes (see Figure 1). We categorized four of the themes as general themes because they were found in all of the interviews. The first general theme, identifying unhealthy behaviors, included client behaviors that the counselors considered as being hindering or damaging. Examples of unhealthy 


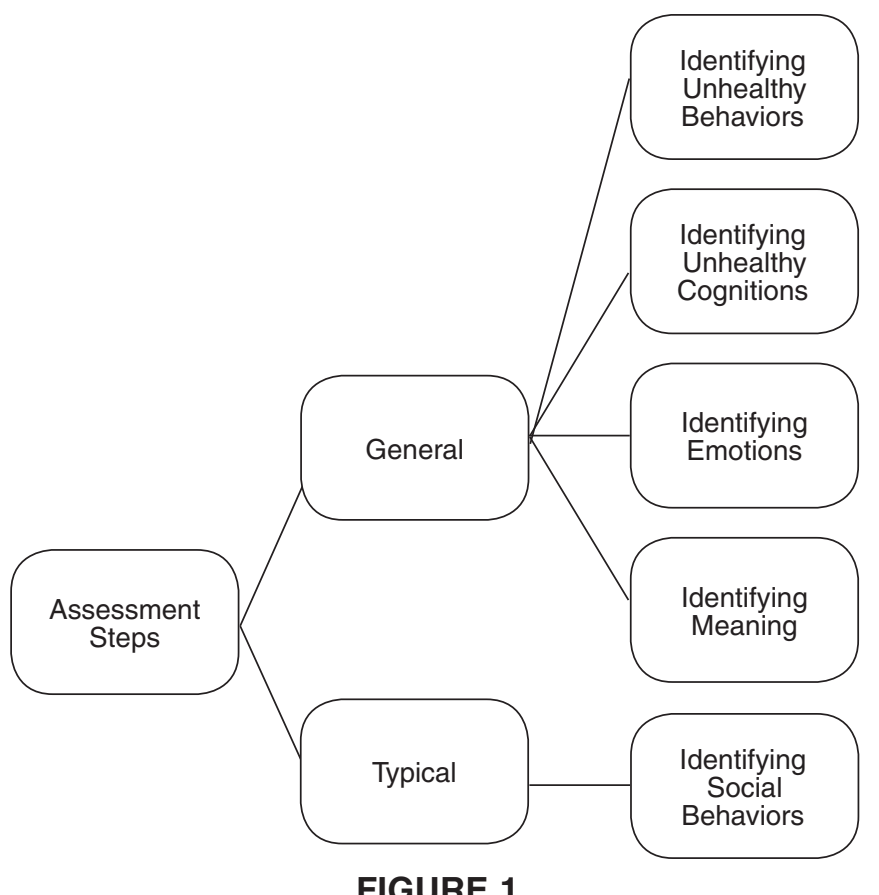

\section{Coding Structure for the Assessment Steps Domain}

behaviors included "playing the victim" as Counselor 4 put it and having a "lack of healthy familial boundaries" as stated by Counselor 3. The counselors also noticed patterns of thinking that were unhealthy. This theme, labeled identifying unhealthy cognitions, consisted of self-perceptions and thinking patterns that drifted toward extremes, such as using all-or-nothing thinking. For example, Counselor 5 stated, "That black-and-white type of thinking she was doing . . . ah ... she either has to take over everything or do nothing." Counselor 2 commented, "She is questioning herself and I'm thinking, 'Well, maybe there is some self-concept things going on that she ... tends to think or perceive herself and others in extremes."”

All of the participants also focused on identifying emotions that the client either directly or indirectly expressed. Counselor 3 observed, "I think that she's saying, 'I'm stuck.' She seems stuck. And when somebody says, 'I'm overwhelmed, I'm stuck,' individuals always have options but they, at that moment, they don't see it. Especially, too, if she's overwhelmed and depressed." Another counselor remarked, "It is like she's exhausted her anger out ... into sadness and disappointment" (Counselor 1). Identifying emotions was important to the counselors because it allowed them to see how receptive the client would be to further intervention. As noted by Counselor 5, "she's in the state a lot of clients are in where they don't see, because they are overwhelmed by negative emotions." All participants also saw deeper layers of client meaning within the story. This theme, labeled identifying meaning, was well represented in Counselor 2's interview: "[We are] getting to the abandonment by both parents instead of her black-and-white 'it's all mom's fault.' ... So I would sort of play on that in helping her recognize ... she's feeling abandoned by both parents." Counselor 4 identified another example: "I think what we are seeing here is some pretty core issues in her functioning and coping and the capacity of maturity and for control." Another counselor described this theme as her "fleshing out some of her control issues" (Counselor 4).

The final theme, identifying social behaviors, was categorized as typical given that we found evidence for it in seven of the nine interviews. In this theme, counselors focused on the client's patterns of interpersonal relating, which included the client's capacity for establishing relational intimacy and how far she drew her boundaries for relating to other people. The counselors noted that the client had "an inability to establish boundaries between her and her parents" (Counselor 4) and that "she is weary of trusting others . . connecting on an intimate level with others" (Counselor 1).

\section{Clinical Impressions}

The domain clinical impressions was composed of four themes (see Figure 2). This domain captured what facets of the client's presentation counselors found clinically significant upon first impression. The first theme, context, was a general theme found in all nine interviews that described each counselor's desire to explore information that provided the backdrop to the client's story. For example, Counselor 6 expressed an interest in exploring further the client's situation with her parents because the counselor perceived the

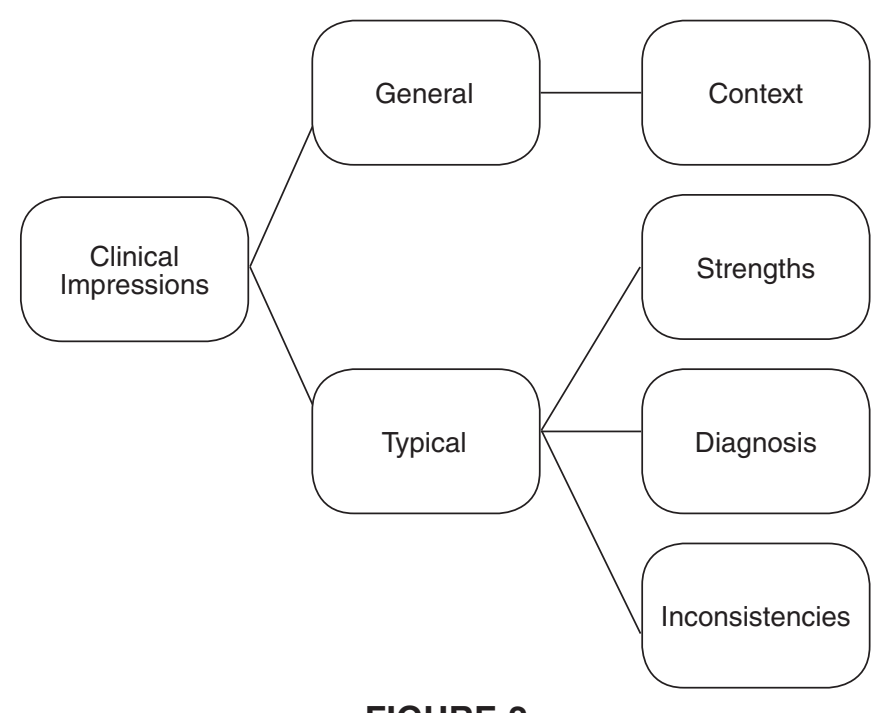

FIGURE 2

\section{Coding Structure for the Clinical Impressions Domain}


client as having a "very dramatic reaction" to a not unusual circumstance. Counselor 4 was intrigued by the client's developmental level and how that may play a part in the types of interventions the counselor could use:

One thing I am really thinking is where she is at developmentally. I would love to know what age she is . . . if her developmental level would play a really important part in the kind of questions I'd ask and what I would be expecting out of her responses.

Counselor 3 desired to explore other "external" factors that were influencing the client and how long the client had been struggling with the situation. The counselors were also interested in the client's cultural background, noting that the client's expression of anger could be different if she was from a particular region of the United States. As Counselor 7 noted, "people in the South are really polite, and um, sometimes that politeness covers up their real feelings."

The next three themes were typical, showing up in five to eight interviews. The first of these was found in eight of the interviews and regarded the client's strengths. These strengths were not always directly alluded to by the client yet were noticeable more so in the way the client discussed the issue. For example, Counselor 7 believed that the client had an advanced capacity to multitask, saying, "She's seeing herself as ... struggling, because look at all the things she is trying to juggle. Which, by the way, she is juggling them! I'd be dropping one or two things, even more, but she's standing by it, and that's amazing." Five counselors made explicit reference to possible diagnoses, including adjustment disorder and major depression. Likewise, five counselors noted various inconsistencies in the client's expression of the issue. For example, Counselor 6 observed that "even though she is kind of expressing anger, it doesn't seem to be coming from a real deep place within her." Counselor 8 also noted inconsistencies in her presentation, stating, "Something about it doesn't seem very congruent, like her affect and her presence." Three of the counselors mentioned the role that countertransference could play in identifying inconsistencies with the client. Counselor 1 reported,

I'm looking for, or listening for, pieces that don't sound like they fit with . . . where she thinks she is versus what I'm experiencing and seeing from her. So using both her and my countertransference ... and more of my experience of her to ... be a more realistic or ... complete picture where she actually is emotionally as opposed to where she believes she needs to be or . . . in the relationships she's talking about.

\section{Treatment Factors}

The domain treatment factors comprised six themes (see Figure 3). Three of these themes were evident in all nine

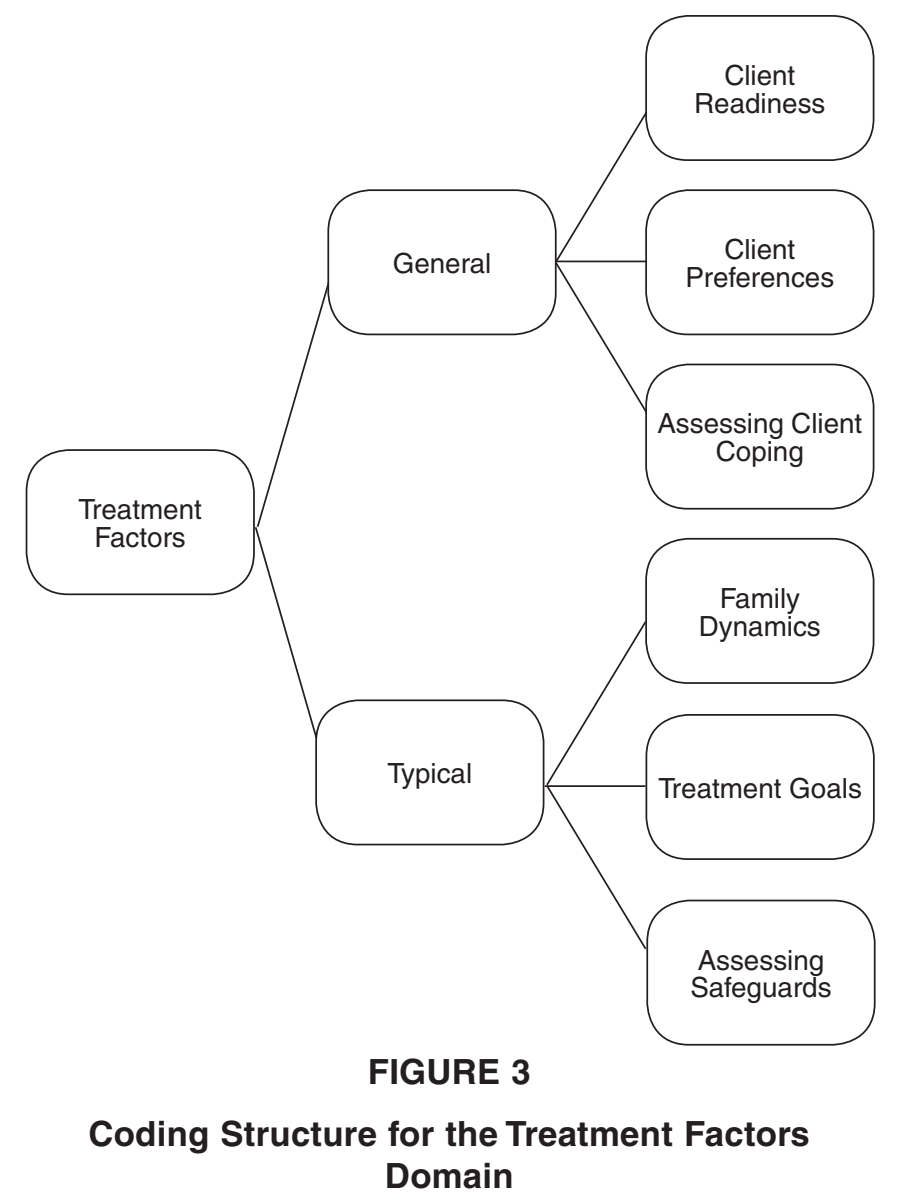

interviews and were categorized as general. First, all of the counselors mentioned the importance of factoring in client readiness to their treatment approach to determine when and how to intervene. For example, Counselor 7 stated,

I would try to mirror that [inconsistencies, perceptions of strength] back. When, when the client is ready to receive it. I would try to mirror that at a time when the client's perception of herself is very distant from my own observation.

In addition to considering how ready the client was for any given treatment approach, all nine counselors mentioned the importance of including client preferences during treatment. The following participant quotes illustrate this theme:

Well, I believe that goals should be a collaboration between the client and counselor, so I'd have to find out what it is that she would like to do. (Counselor 2)

Well, the next steps would be to have a sense of what it is that she needs now. I can’t do that ... so all I can give you are assumptions, reluctant solutions. . . . So all I can give you right now are, are ideas. The most important question would be ... "What do you need from this? What's needed? What's next?" (Counselor 7) 
Treatment goals . . clearly you would have to make sure these were her goals as well. (Counselor 9)

The final general theme was assessing client coping. All nine counselors made reference to the client's coping resources and how they would try to leverage them during treatment planning. Counselor 5 provided a running list of possible avenues of coping: "In terms of potential coping mechanisms to draw from, client mentioned meditation, she's mentioned spirituality, she's mentioned a social group, those are the things I'm starting to lean toward if she's asking for my help."

The final three themes within the domain treatment factors were typical. Eight of the nine counselors mentioned family dynamics, such as recognizing the potential influence of occupying a familial role (e.g., a peacemaker) and how that could contribute to the client's problem and the counselor's use of potential treatment recommendations. Counselor 3 described this process as exploring "interpersonal and interactions between family members and maybe some type of pattern." Seven counselors started moving into the direction of conceptualizing some potential treatment goals to work on in collaboration with the client's views of what was important for her to change. For example, Counselor 4 stated, "I think the goals really are to start to take a look at the changes she's willing to take with her life, as well as becoming more in tune with her own needs." The final theme, assessing safeguards, was mentioned by five counselors and included exploring certain phrases in the client's description of the issue that might suggest the client's potential for harm to self or others.

\section{Treatment Strategies}

The final domain we identified, treatment strategies, was made up of four themes (see Figure 4). Three of the themes were categorized as general, and one was identified as typical. The first theme, developing the relationship, captured areas of the interviews in which the counselors mentioned the need to create a solid working alliance as the primary means of intervention. For example, Counselor 5 remarked, "It's important for me to ensure that I've heard her sufficiently. I don't want her to feel dismissed. Or have her concerns belittled by me moving too quickly into more of an action-oriented intervention." Counselor 1 picked up on the client's tendency to cautiously trust other people and reflected on how that might influence the development of the therapeutic relationship:

Um, I would probably want to make sure that I'm a presence in the room. That I'm me and sort of an individual person as a presence in the room. Uh . . . so that . . because I think, I think she's a client who . . . I think she's going to take a long time to develop a therapeutic relationship ... for her to really trust me, for her to ... um . . . for her to see her role in her own issues.

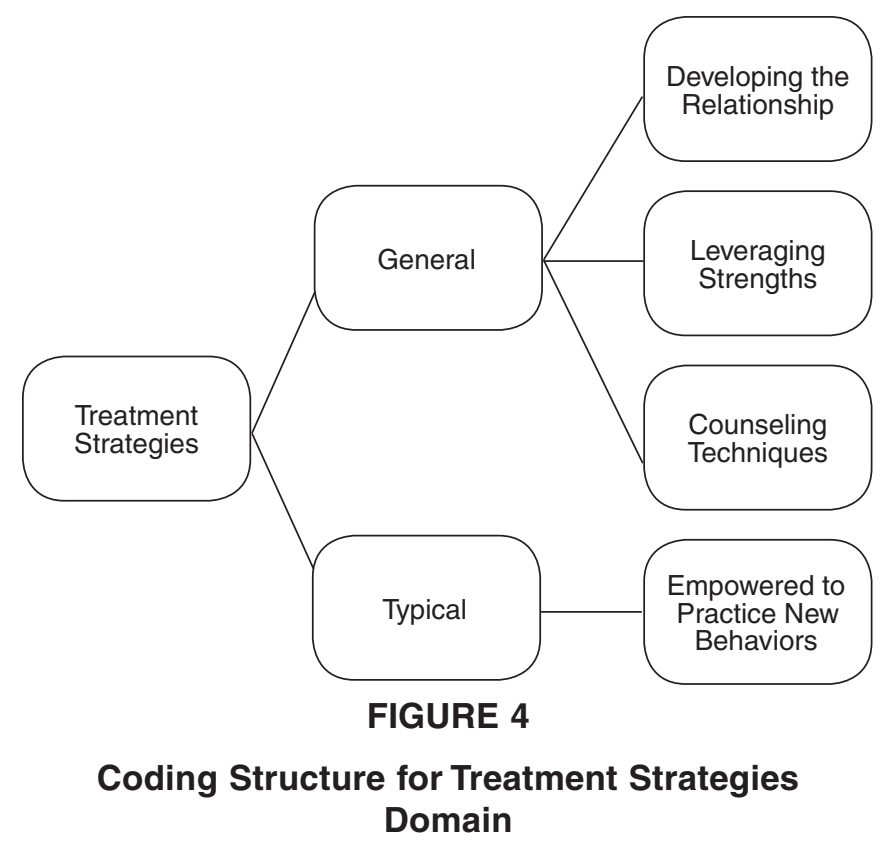

The second general theme we found, leveraging strengths, captured moments in the interviews in which the counselors targeted specific strengths the client possessed (e.g., the client's insight and emotional self-awareness) as possible resources for incorporating into their treatment strategies. For example, Counselor 2 said,

I think I would appeal to her, you know, to her intelligence. Um, and um, and try to, um, get her to recognize the inconsistencies in her thinking, ah, which I think she could probably see in a counselor if she probably would recognize them too.

The goal of leveraging the client's strengths was to increase her coping skills and tap into the client's innate capacity for growth and resilience. Counselor 5 spoke about encouraging the client to harness resources within her life that are inherently pleasurable by "implementing components of those things that have brought her pleasure, joy, satisfaction ... I would look at trying to help her to identify pieces of those that she could implement without too much effort."

The final general theme in this domain captured a variety of counseling techniques that the counselors wanted to use to intervene with the client. Some counselors mentioned how they wanted to reflect back to the client both the emotional content of the narrative and some of the implicit meaning they were detecting. In terms of emotional content, Counselor 2 said, "One thing that I think will have to be addressed down the line is the client's anger towards her parents for being so irresponsible." In terms of meaning, Counselor 1 remarked, "I want to jump in and respond to sort of underlying messages that the client is sending, not just the surface ... stuff that she is going through," 
which ultimately related to her sense of abandonment and being "stuck in a future and past orientation, rather than a present orientation." Other counselors made some allusion to reframing the client's perspective of the problem to activate her hope in the future, or at least see that she has more options to choose from beyond the limited number of responses she is accustomed to using. For example, Counselor 6 commented,

I think that might push her a little bit more to look at her choices that she has within the family and the fact that she's not going to have a whole lot of control on how her other family members deal with it.

The counselors also referred to more advanced skills, such as challenging or addressing inconsistencies. For example, Counselor 2 indicated that

I would immediately start working on inconsistencies that she's said. The one, "I really can't take care of myself because" ... on the one hand ... on the other hand "I'm falling apart and I'm drowning," and so those, that's kind of an inconsistency that if she doesn't take care of herself, then who is going to hold things together?

In addition, the participants emphasized the importance of continuing to develop, expand, and probe deeper into the client's description of the problem to create a richer understanding. Counselor 6 described it as

trying to just listen, trying to hear the whole ... take time to let the story unfold a little bit and get a sense of her perception of the problem ... how realistic do her viewpoints seem in the facts that she was presenting.

The counselors also referred to wanting to shift the focus of the session to the client's present experience (i.e., immediacy), either to the problem being discussed or to the relationship between the counselor and the client. For example, Counselor 1 stated,

I think at first it's fine to let her . . . kind of begin to let her tell her narrative and her story, but you know my approach is more, more emotion-focused . . . um, present-oriented approach, so . . . while I take value in . . . in her narrative, or, you know, the examples she is using, I'm really not going to let her go for that long. I'm really going to check, check out what is happening in the room with her.

Using visual aids (e.g., a genogram) was the last technique that the counselors mentioned. They described using it to help the client see the influence of her family dynamics on her current distress, thus alleviating the client of a sense of sole ownership for her pain. Counselor 3 indicated a desire to use a visual aid as part of a brainstorming intervention:

I would assess for that [depression] and, uh, if that's not the case, then I would move on and do a little brainstorming on the white board for the visual - just to make sure that's a visual kind of representation in front of her. The brainstorming possible solutions to her situation.

Empowered to practice new behaviors, the typical theme in this domain, was evident in eight of the nine interviews. In context, the new behaviors the counselors identified were primarily directed at shifting the client's typical caretaking energy that was focused on her family to self-care. A particularly rich example of this theme was extracted from Counselor 1's interview:

I would want to find ways to guide her to interject those things towards herself. You know, she spends a lot of time transmitting her energy toward all these other people in her life, and, you know, I'm, I'm wondering where does she . . . fall into her own world, and so I would want to see how ... she can turn the things that she does for others, the caretaking and the, you know, being really defensive and protective of her sister. How can she do that for herself?

\section{Discussion}

In this study, we qualitatively analyzed the decision-making process of nine experienced professional counselors. We conducted this study to better understand what information counselors focus on when developing their treatment plans. This study required our participants to view a counseling scenario and think out loud (pausing the session if needed) about their intuitions and interpretations of a client's presenting problem. By analyzing their responses using CQR, we were able to identify four separate domains (assessment steps, clinical impressions, treatment factors, and treatment strategies) that informed their treatment planning process.

An examination of the general and typical coding structure for each domain (see Figures 1-4) demonstrates that our sample of counselors shared more themes in common than themes that were unique to each participant. None of our domains had variant codes - codes that were evident in only one or two participants' treatment plans. Furthermore, when comparing across the domains, we found that the number of themes present in all interviews (i.e., general themes) far outnumbered those codes that were spread out across a few participants. Thus, the majority of what composed the coding pool was evident in the experiences of all of the counselors. This finding supports previous research investigating experienced therapists' reactions to clinical scenarios (Eells, 1999; Kealy et al., 2015). For example, a Q-methodology study 
of experienced clinicians' decision-making responses to a standardized sample of clinical material were clustered into a single common factor despite representing nine distinct theoretical schools (Fox et al., 2016). Fox and colleagues' (2016) sample characteristics were similar to those of the current study in the sense that participants had accumulated 10 years of experience and represented a heterogeneous sample of theoretical perspectives. Our findings affirm that it is likely that experienced counselors are more alike than they are different when they make treatment planning decisions.

A review of the findings also indicates that our sample of experienced counselors did not adhere strictly to a medical model in their treatment planning processes. The medical model certainly surfaced as one area of consideration (as in the case of diagnosis - a typical theme within the domain clinical impressions), but the complexity of information the participants sorted through could not be confined under a metalayer of medical model terminology. It is possible that if the same counselors analyzed a vignette in which there was more severe pathology with a different client, then perhaps that would have shifted the focus of their conceptualization or at least made medical model terminology more central. Because we did not collect an assessment of the client's pathology beforehand, this remains an open question and one worthy of future investigation. However, none of the participants believed that the client brought forward clinically insignificant or irrelevant material that should never be the focus of therapy. Instead, each participant was able to conceptualize areas for growth that could be worked on in subsequent counseling sessions. Thus, even if more severe pathology was evidenced in the client's session, those areas that were valid for exploration would likely not be removed entirely from a treatment plan. This raises a logical question: If the participants' treatment planning process cannot be explained using the parameters of the medical model, how can it be explained?

After examining the literature, we believe that the treatment planning process we observed in this study most closely aligns with Young's (2012) REPLAN model and Wampold and Imel's (2015) Contextual Model. First, it appears that the participants in our study took a stratified approach to assessing the client's presenting problem. This stratified approach is apparent when examining the domain assessment steps. Under the general themes in Figures 1-4, the coding structure is almost perfectly aligned with Young's REPLAN model in that the themes began with identifying the problem, but then progressed through layers of understanding the problem through cognitions, to emotions, and to identifying meaning. These stratified layers of assessment, according to Young, provide the raw material for empathy and reflection skills; in turn, these skills lead to the foundation of all counseling interventions - creating and maintaining a strong therapeutic relationship.
This approach also aligns closely with Wampold and Imel's (2015) Contextual Model. The first pathway in the Contextual Model, the real relationship, could be summarized as the need for authentic human connection with the counselor and coincides with the centrality of the therapeutic relationship, as in Young's (2012) REPLAN model. This was certainly evident in our findings, given that all of the participants in some way mentioned the importance of the relationship for treatment strategies (see Figure 4). The second pathway in the Contextual Model, expectations, is more than simply believing that therapy will help; it involves believing in the explanatory framework offered by the counselor's approach to working through the problem and requires that the client be in agreement with the counselor about the goals of therapy. This concept is almost fully encapsulated in Young's activation of client expectations, hope, and motivation (the "A" in REPLAN). Similarly, all of the participants in our study indicated that they regarded client readiness and client preferences as important treatment factors (see Figure 3). The third and final pathway, specific ingredients, refers to those specific therapeutic actions that engage the client in health-producing processes. This concept is also consistent with Young's REPLAN model, which requires the counselor to select therapeutic strategies based on the common factors. This pathway is accounted for in the theme counseling techniques within the domain treatment strategies (see Figure 4).

\section{Limitations}

As is the case with all research, this study has several limitations. First, we did not include a diverse sample of clients for the counselors to respond to. This lack of diversity could have contributed to the treatment planning processes being less varied in nature and therefore influencing how often we could find and label thematic codes across counselors. Second, we did not collect more complex information (e.g., an assessment battery using psychometrically reliable and valid instruments) about the client's presenting problem beyond the client's narrative description during the session itself. Therefore, it is difficult to make firm conclusions about how central features of pathology would be if a different type of client were the focus of the treatment planning process. Third, self-report bias may exist in our findings. Participants may have reported what they thought were best practices rather than what they did in treatment because they knew that they were being recorded. Finally, although our sample size was sufficient for the analysis, recruiting more participants from diverse settings may have provided richer descriptions of the participants' experiences, thus increasing the trustworthiness and transferability of the findings.

\section{Implications for Counseling and Future Research}

One of the benefits to qualitative research is that it provides depth in the understanding of seldom-explored phenomena 
(Hays \& Singh, 2012; Hays \& Wood, 2011; Hunt, 2011). Treatment planning is an area with little research in counseling (Falvey et al., 2005; Witteman \& Koele, 1999; Witteman \& Kunst, 1997), and through the findings of this study, we can gain a deeper understanding into the process by which experienced counselors make treatment planning decisions. These findings hold implications for clinical practice and potential research.

In terms of clinical implications, our findings further confirm that experienced counselors, regardless of theoretical orientation, are more similar in clinical decision making than they are different. Traditionally, treatment planning is taught as being based on diagnosis or theory (Seligman, 1996; Seligman \& Reichenberg, 2014; Wampold \& Imel, 2015); however, in our sample of experienced counselors, decisions were based primarily on contextual factors (e.g., clinical impressions, treatment factors, concerns identified in assessment). Diagnosis influenced treatment decisions, but participants considered it less important than other factors. This finding is consistent with the existing literature on treatment effectiveness (Lambert \& Ogles, 2014; Wampold \& Imel, 2015). Therefore, counselors should consider a broadening of their repertoire in clinical decision making and treatment planning to allow for the consideration of contextual factors in addition to theory and diagnosis when making treatment decisions. Supervisors and counselor educators should also consider methods for instructing novice counselors on how to take context into account in treatment planning. Finally, our findings support the use of systematic common factors approaches, such as the aforementioned REPLAN model (Young, 2012) and Contextual Model (Wampold \& Imel, 2015).

In terms of research, this study presents a preliminary investigation into the treatment planning process. Future research should attempt to replicate these findings with a different sample of clinicians and various case scenarios. Furthermore, we suggest that future researchers examine the treatment planning process using a quantitative approach. Whereas this study provides valuable information into the experiences of treatment planning, a quantitative approach would allow for generalizable findings and an examination of statistical significance.

\section{Conclusion}

We believe that this study offers a useful framework for future research in treatment planning. We acknowledge that this line of research is still in its infancy and hope that future researchers will continue to explore treatment planning methods and clinical decision making to develop a stronger understanding of how to offer comprehensive and effective treatment. Furthermore, counselor training programs should consider offering training on contextual approaches to treatment planning.

\section{References}

American Counseling Association. (2014). ACA code of ethics. Alexandria, VA: Author.

Baker, T. B., McFall, R. M., \& Shoham, V. (2008). Current status and future prospects of clinical psychology: Toward a scientifically principled approach to mental and behavioral health care. Psychological Science in the Public Interest, 9, 67-103. doi:10.1111/j.1539-6053.2009.01036.x

Beutler, L. E., Forrester, B., Gallagher-Thompson, D., Thompson, L., \& Tomlins, J. B. (2012). Common, specific, and treatment fit variables in psychotherapy outcome. Journal of Psychotherapy Integration, 22, 255-281. doi:10.1037/a0029695

Council for Accreditation of Counseling and Related Educational Programs. (2015). 2016 CACREP Standards. Alexandria, VA: Author.

Eells, T. D. (1999). What do we know about master therapists? Journal of Psychotherapy Practice and Research, 8, 314-317.

Falvey, J. E., Bray, T. E., \& Hebert, D. J. (2005). Case conceptualization and treatment planning: Investigation of problem-solving and clinical judgment. Journal of Mental Health Counseling, 27, 348-372. doi:10.17744/mehc.27.4.cw8uyjum3w4dnfmn

Fox, J., Hagedorn, W. B., \& Sivo, S. A. (2016). Clinical decisionmaking and intuition: A task analysis of 44 experienced counsellors. Counselling and Psychotherapy Research, 16, 244-255. doi:10.1002/capr.12084

Frank, J. D., \& Frank, J. (1991). Persuasion and healing: A comparative study of psychotherapy (3rd ed.). Baltimore, MD: Johns Hopkins University Press.

Gaudiano, B. A., Brown, L. A., \& Miller, I. W. (2011). Let your intuition be your guide? Individual differences in the evidencebased practice attitudes of psychotherapists. Journal of Evaluation in Clinical Practice, 17, 628-634. doi:10.1111/j.13652753.2010.01508.x

Hays, D. G., \& Singh, A. A. (2012). Qualitative inquiry in clinical and educational settings. New York, NY: Guilford Press.

Hays, D. G., \& Wood, C. (2011). Infusing qualitative traditions in counseling research designs. Journal of Counseling \& Development, 89, 288-295. doi:10.1002/j.1556-6678.2011. tb00091.x

Hill, C. E. (2012). Consensual qualitative research: A practical resource for investigating social science phenomena. Washington, DC: American Psychological Association.

Hill, C. E., Knox, S., Thompson, B. J., Williams, E. N., Hess, S. A., \& Ladany, N. (2005). Consensual qualitative research: An update. Journal of Counseling Psychology, 52, 196-205. doi:10.1037/0022-0167.52.2.196

Hill, C. E., Thompson, B. J., \& Williams, E. N. (1997). A guide to conducting consensual qualitative research. The Counseling Psychologist, 25, 517-572. doi:10.1177/0011000097254001

Hunt, B. (2011). Publishing qualitative research in counseling journals. Journal of Counseling \& Development, 89, 296-300. doi:10.1002/j.1556-6678.2011.tb00092.x 
Kealy, D., Goodman, G., Rasmussen, B., Weideman, R., \& Ogrodniczuk, J. S. (2015). Therapists' perspectives on optimal treatment for pathological narcissism. Personality Disorders: Theory, Research, and Treatment. Advance online publication. doi: $10.1037 /$ per0000164

Lambert, M. J. (2007). Presidential address: What we have learned from a decade of research aimed at improving psychotherapy outcome in routine care. Psychotherapy Research, 17, 1-14. doi:10.1080/10503300601032506

Lambert, M. J. (2013a). Bergin and Garfield's handbook of psychotherapy and behavior change (6th ed.). Hoboken, NJ: Wiley.

Lambert, M. J. (2013b). Outcome in psychotherapy: The past and important advances. Psychotherapy, 50, 42-51. doi:10.1037/ a 0030682

Lambert, M. J., \& Ogles, B. M. (2014). Common factors: Post hoc explanation or empirically based therapy approach? Psychotherapy, 51, 500-504. doi:10.1037/a0036580

Laska, K. M., Gurman, A. S., \& Wampold, B. E. (2014). Expanding the lens of evidence-based practice in psychotherapy: A common factors perspective. Psychotherapy, 51, 467-481. doi:10.1037/a0034332

Laska, K. M., \& Wampold, B. E. (2014). Ten things to remember about common factor theory. Psychotherapy, 51, 519-524. doi: $10.1037 / \mathrm{a} 0038245$

Luborsky, L., Rosenthal, R., Diguer, L., Andrusyna, T. P., Berman, J. S., Levitt, J. T., . . Krause, E. D. (2002). The dodo bird verdict is alive and well-Mostly. Clinical Psychology: Science and Practice, 9, 2-12. doi:10.1093/clipsy/9.1.2

Lucock, M. P., Hall, P., \& Noble, R. (2006). A survey of influences on the practice of psychotherapists and clinical psychologists in training in the UK. Clinical Psychology \& Psychotherapy, 13, 123-130. doi:10.1002/cpp.483

Marcus, D. K., O’Connell, D., Norris, A. L., \& Sawaqdeh, A. (2014). Is the dodo bird endangered in the 21 st century? A meta-analysis of treatment comparison studies. Clinical Psychology Review, 34, 519-530. doi:10.1016/j. cpr.2014.08.001
Norcross, J. C., \& Wampold, B. E. (2011). Evidence-based therapy relationships: Research conclusions and clinical practices. Psychotherapy, 48, 98-102. doi:10.1037/a0022161

Qualtrics [Computer software]. Retrieved from https://www.qualtrics.com/

Rosenzweig, S. (1936). Some implicit common factors in diverse methods of psychotherapy. American Journal of Orthopsychiatry, 6, 412-415. doi:10.1111/j.1939-0025.1936.tb05248.x

Seligman, L. (1996). Diagnosis and treatment planning in counseling (2nd ed.). New York, NY: Plenum Press.

Seligman, L., \& Reichenberg, L. W. (2014). Selecting effective treatments: A comprehensive systematic guide to treating mental disorders (4th ed.). Hoboken, NJ: Wiley.

Swift, J. K., Callahan, J. L., Ivanovic, M., \& Kominiak, N. (2013). Further examination of the psychotherapy preference effect: A meta-regression analysis. Journal of Psychotherapy Integration, 23, 134-145. doi:10.1037/a0031423

Wampold, B. E. (2013). The good, the bad, and the ugly: A 50-year perspective on the outcome problem. Psychotherapy, 50, 16-24. doi:10.1037/a0030570

Wampold, B. E. (2015). How important are the common factors in psychotherapy? An update. World Psychiatry, 14, 270-277. doi:10.1002/ wps. 20238

Wampold, B. E., Ahn, H., \& Coleman, H. L. K. (2001). Medical model as metaphor: Old habits die hard. Journal of Counseling Psychology, 48, 268-273. doi:10.1037/0022-0167.48.3.268

Wampold, B. E., \& Imel, Z. E. (2015). The great psychotherapy debate: The evidence for what makes psychotherapy work (2nd ed.). New York, NY: Routledge.

Witteman, C., \& Koele, P. (1999). Explaining treatment decisions. Psychotherapy Research, 9, 100-114. doi:10.1080/10503309912331332621

Witteman, C., \& Kunst, H. (1997). Planning the treatment of a depressed patient. Clinical Psychology \& Psychotherapy, 4, 157-171. doi:10.1002/(SICI)1099-0879

Young, M. E. (2012). Learning the art of helping: Building blocks and techniques (5th ed.). Boston, MA: Pearson. 